\title{
Second Mesiobuccal Canal Treatment in a Predoctoral Dental Clinic: A Retrospective Clinical Study
}

\author{
Marcelo Santos Coelho, DDS, MSc; Jeffrey M. Parker, DMD; Peter Z. Tawil, DMD, MS, \\ FRCD $(C)$, Dip ABE
}

Abstract: The aim of this retrospective clinical study was to evaluate the location and treatment of second canals in mesiobuccal roots (MB2) of first and second maxillary molars in a predoctoral endodontic clinic by the graduating classes of 2008 to 2015. These results were compared to similar clinical studies. Included in the study were 368 root canal treatments performed by 310 third- and fourth-year dental students at one U.S. dental school. All cases were done under faculty supervision, and the students were instructed to use dental loupe magnification. Students' evaluation sheets were used to deteremine the total MB2 canals treated in first and second maxillary molars. The results showed that, overall, $72.55 \%$ of the teeth had an MB2 canal treated. The frequency was higher in first molars $(75.91 \%)$ than in second molars $(56.92 \%)(\mathrm{p}<0.05)$. Third-year students were able to detect 39 MB2 canals in 57 maxillary molars $(68.42 \%)$, while fourth-year students detected $228 \mathrm{MB} 2$ canals in 311 teeth $(73.31 \%)$ $(\mathrm{p}>0.05)$. Under proper supervision by experienced endodontists, these dental students were capable of treating MB2 canals in maxillary molars. The frequency of MB2 canals located and treated by dental students with the assistance of experienced professionals was higher in first than in second molars. No significant difference was found between third- and fourth-year students. The incidence of MB2 canals located and treated in this study was found to be similar to that in other clinical studies.

Dr. Coelho is Visiting Scholar, Department of Endodontics, School of Dentistry, University of North Carolina at Chapel Hill; Dr. Parker is a third-year resident, Department of Endodontics, School of Dentistry, University of North Carolina at Chapel Hill; and Dr. Tawil is Graduate Program Director, Department of Endodontics, School of Dentistry, University of North Carolina at Chapel Hill. Direct correspondence to Dr. Marcelo Santos Coelho, Department of Endodontics, University of North Carolina at Chapel Hill School of Dentistry, 1098 Old Dental Building, CB\#7450, Chapel Hill, NC 27599-7450; coelho_marcelo@yahoo.com.br.

Keywords: dental education, endodontics, root canal treatment, maxillary molar, mesiobuccal root

Submitted for publication 10/19/15; accepted 12/26/15

$\mathrm{S}$ uccess in root canal treatment (RCT) is dependent on the appropriate cleaning, shaping, and filling of the entire root canal system. ${ }^{1}$ During RCT, errors may occur, leading to treatment failure; missed canals are one of the most frequent procedural errors leading to unsuccessful outcomes. ${ }^{2}$ Maxillary molars may present a challenge to clinicians due to the complex anatomy that can lead to failure in locating the second mesiobuccal (MB2) canal. Not locating this canal can decrease the likelihood of long-term success. ${ }^{3}$

In dental education, lectures on the internal endodontic anatomy of teeth and preclinical and clinical training teach students to understand and locate MB2 canals. ${ }^{4,5}$ Other factors that may influence the clinical location of MB2 canals are the clinical experiences of endodontic specialists ${ }^{6}$ and postgraduate students, ${ }^{7}$ use of dental loupes, ${ }^{8,9}$ the dental operating microscope (D.O.M.), ${ }^{10,11}$ and ultrasonic tips. ${ }^{12}$ Use of an intraoral camera as a tool to help in locating MB2 canals has also been tested. ${ }^{13}$
Studies have addressed the frequency of locating MB2 canals in vitro ${ }^{14,15}$ and in vivo. ${ }^{6,16-19}$ Vertucci, in an in vitro study, described the first maxillary molar as having $55 \%$ of MB2 canals and the second molar as having $29 \% .{ }^{20}$ Kulild and Peters reported $96.1 \%$ of MB2 canals in first maxillary molars and $93.7 \%$ in maxillary second molars in a study with extracted teeth. ${ }^{15}$ A review found that laboratory studies usually presented higher incidence of MB2 canals in first molars, from $25 \%$ to $96 \%$, than in clinical studies, which ranged from $18.6 \%$ to $80.3 \% .^{21}$

In their clinical studies, Sempira and Hartwell reported that graduate students located $33.1 \%$ of MB2 canals in first molars and $24.3 \%$ in second molars, ${ }^{17}$ while Hartwell et al. found $70.2 \%$ of maxillary first molars had four canals that were located by graduate students. ${ }^{18} \mathrm{~A}$ clinical study in RCT done by an endodontic specialist reported $93 \%$ of first molars having MB2 canals and $60.4 \%$ of second molars. ${ }^{6}$ Wolcott et al. found that $61.0 \%$ of MB2 canals in maxillary first molars and $36.0 \%$ in maxillary 
second molars were located during initial treatment and retreatment cases performed by five endodontic specialists. $^{22}$

The frequency of MB2 canals located in extracted teeth by predoctoral dental students has been previously reported. ${ }^{4,11}$ However, the frequency of MB2 canals located and treated by predoctoral dental students in a clinical setting is still unclear. The aim of this retrospective clinical study was to evaluate the frequency of MB2 canals in maxillary first and second molars located and treated by thirdand fourth-year dental students who were assisted by an endodontic attending faculty member over an eight-year period in the University of North Carolina at Chapel Hill School of Dentistry clinic.

\section{Materials and Methods}

This study was granted an exempt status by the Institutional Review Board Office of Human Research Ethics of the University of North Carolina at Chapel Hill. The data were collected from evaluation sheets of dental students who had treated 368 patients who underwent primary root canal treatments of first and second maxillary molars from June 2007 to May 2015 in the dental school's predoctoral endodontic clinic.

The treatments were performed by 310 dental students who had received the same preclinical training involving simulated plastic teeth and extracted human teeth. The students had also attended six hours of lectures about the internal anatomy of teeth and endodontic access. Data from eight classes were included in this study: the graduating Class of 2008 through the graduating Class of 2015. Students' evaluation sheets available from 2007 to 2015 were assessed and analyzed in the search for treatments completed in maxillary molars. Every maxillary molar treated was classified according to the location and treatment of an MB2 canal, the type of tooth (first or second molar), and the student year (third or fourth year).

In this clinical setting, the treatment of molars is only performed by students who have completed at least one successful treatment without faculty assistance on a single-rooted tooth. Only cases of primary RCT were assigned to the dental students; both third- and fourth-year students performed RCT in first and second molars. Complex cases that had severe curvatures or calcified canals or retreatment cases were referred to the graduate clinic.
After anesthesia, the teeth were isolated with a rubber dam, and the endodontic accesses were performed. A conventional rhomboid-shape access allowing visualization of all the canal orifices was recommended. All cases were done under faculty supervision, and the students were instructed to use dental loupe magnification (2.5x to $3.5 \mathrm{x})$ during treatment. After the endodontic access was completed by polishing with an Endo-Z bur, the search for MB2 canals was completed with the aid of \#2 surgical length bur on a low-speed handpiece. If an MB2 canal was not located in the first visit, the student was required to search for it in the next appointment. Supervision by an endodontic attending faculty member was provided in all steps of the treatment, including the search for MB2 canals. If the MB2 canal was not detected by the dental student, the use of the D.O.M. was available for use by the attending endodontic faculty. All the faculty members were endodontic specialists; even when a third-year endodontic resident was covering the endodontic student clinic, the work was always overseen by the attending endodontic faculty.

The presence of the MB2 canal was confirmed and registered on the students' evaluation sheets. Only canals located, instrumented, and filled were considered as treated. These MB2 canals were either fully negotiable up to the working length or merged to the main mesiobuccal canal. Tooth type (maxillary first or second molar), tooth distribution among students, and the student's year (third- or fourthyear) were also recorded. The Fisher's exact test was used for statistical analysis with a significance level of 0.05 .

\section{Results}

A total of 368 maxillary molars (303 first molars and 65 second molars) were treated during the years included in the study (Table 1). Thirdyear students performed treatments in 57 teeth, and fourth-year students performed treatment in 311 . The third-year students treated 49 first molars and eight second molars; the fourth-year students treated 254 first molars and 57 second molars. The distribution of first and second molars was equivalent for third- and fourth-year students $(\mathrm{p}>0.05)$.

Overall, an MB2 canal was located and treated in 267 teeth $(72.55 \%)$. The frequency of MB2 canals found in 303 first molars (75.91\%) was higher than in 65 second molars $(56.92 \%)(\mathrm{p}<0.05)$. Third-year 
students were able to treat MB2 canals in $68.42 \%$ of the maxillary molars and fourth-year students in $73.31 \%$. This difference was not statistically significant ( $p>0.05$ ). The specific percentage of canals located by the students in first and second maxillary molars is shown in Table 2.

\section{Discussion}

Previous studies reporting the incidence of MB2 canals in maxillary molars vary considerably. It is important to take into consideration whether the studies were in vitro or in vivo. In an in vitro study, Kulild and Peters found a frequency of $96.1 \%$ of MB2 canals in first molars and $93.7 \%$ in second molars. ${ }^{15}$ In vitro studies usually present a higher incidence of a second canal in the mesiobuccal root than clinical studies. ${ }^{21}$ In our in vivo retrospective clinical study, the results showed a lower frequency than in the Kulild and Peters study: $75.91 \%$ for first molars and $56.92 \%$ for second molars. This was in agreement with other clinical studies among graduate students ${ }^{7,17,18}$ and experienced professionals. ${ }^{8,23} \mathrm{In}$ an in vitro study, teeth are manipulated with direct vision. In addition, the methodology adopted by Kulild and Peters included tooth sectioning. There was no difference in the frequency of first and second maxillary molars in their study; however, our findings suggested that, clinically, the frequency of MB2 canals was higher in maxillary first molars than in second molars, which is in accordance with other clinical studies. ${ }^{6-8,17}$

Park et al., in an in vitro study, reported that predoctoral students located MB2 canals in $14.8 \%$

Table 1. Distribution of the 368 teeth treated according to tooth type by students' year and total

\begin{tabular}{lccc} 
Tooth Type & Third Year & Fourth Year & Total \\
\hline 1st molar & 49 & 254 & 303 \\
2nd molar & 8 & 57 & 65
\end{tabular}

Table 2. Percentage of second canals in mesiobuccal roots located by third- and fourth-year students in first and second maxillary molars

\begin{tabular}{lccc} 
Tooth Type & Third Year & Fourth Year & Total \\
\hline 1st molar & $73.47 \%$ & $76.38 \%$ & $75.91 \%$ \\
2nd molar & $37.50 \%$ & $59.65 \%$ & $56.92 \%$
\end{tabular}

of first molars and $16.3 \%$ of second molars with $2 \mathrm{x}$ magnification loupes. ${ }^{4}$ The use of a D.O.M. has been shown to help canal location in extracted teeth. ${ }^{24}$ Yoshioka et al. found in vitro that the use of the microscope and dentin removal increased the amount of canals located in both first and second maxillary molars. ${ }^{11}$ The rate of MB2 canals in first and second molars in their study was $51.0 \%$ and $34.6 \%$, respectively; and tooth clearing showed that students had an effectiveness of locating MB2 canals in $83 \%$ of first molars and $89 \%$ of second molars. In spite of the importance of magnification, the use of loupes or microscopes by dental students is still controversial. Bowers et al. found that microscopes were superior to loupes in a precision manual dexterity test, but operators with less experience with microscopes (less than three years) required more time to complete the test. ${ }^{25}$ Rampado et al. showed in vitro the benefit in locating canals using the operating microscope by dental students. ${ }^{10}$ The use of $2.5 x$ to $3.5 x$ magnification loupes was recommend to students in the predoctoral clinic in their study. In our study, a microscope was available for use by the attending endodontic faculty when necessary.

The operator experience in our study was an important factor that impacted the canal location (Table 3). A study performed by an experienced endodontist evaluated the configuration of maxillary molars over eight years. ${ }^{6}$ During the initial assessment while using $2.5 \mathrm{x}$ and $4.0 \mathrm{x}$ magnification loupes, the location of MB2 canals in first $(73.2 \%)$ and second molars $(50.7 \%)$ were similar to the findings in our study. The later use of the D.O.M. along with more years of experience resulted in a higher percentage of MB2 canals $(93.0 \%)$ in first molars. Another clinical study among endodontic residents, who were in a two-year program, showed that their ability to locate MB2 canals increased in the last six months of the program when compared to the first six months. ${ }^{7}$ In our study, there was no statistically significant difference between third- and fourth-year students in locating and treating MB2 canals. The one-year difference in experience and the low number of treatments done by each dental student in our study was probably not sufficient to influence the results. Sempira and Hartwell in a clinical study among graduate students evaluated 200 maxillary molars treated in an 18-month interval. ${ }^{17}$ The incidence of MB2 canals in first molars was $33.1 \%$ and $24.3 \%$ for second molars. In spite of the magnification ranging from $2 x$ to $16 x$ provided by the D.O.M., the rate of two canals in the MB root was not remarkable. The 


\section{Table 3. Clinical studies presenting the percentage of extra canals in first and second molars}

\begin{tabular}{lcclc} 
Clinical Study & 1st Molar & 2nd Molar & Canal Status & Experience \\
\hline Hartwell and Bellizzi* & $18.6 \%$ & $9.6 \%$ & Obturated & Specialist \\
Neaverth et al. & $77.2 \%$ & $\mathrm{n} / \mathrm{a}$ & Obturated & Specialist \\
Weller and Hartwell* & $39.0 \%$ & $21.4 \%$ & Located and obturated & Specialist \\
Fogel et al. & $71.2 \%$ & $\mathrm{n} / \mathrm{a}$ & Located and treated & Specialist \\
Zaatar et al. & $40.6 \%$ & $23.9 \%$ & Treated & Specialist \\
Stropko & $93.0 \%$ & $60.4 \%$ & Instrumented and filled & Specialist \\
Sempira and Hartwell & $33.1 \%$ & $24.3 \%$ & Negotiated and obturated within & Graduate student \\
& & & 4 mm from the apex & Specialist \\
Wolcott et al. & $61.0 \%$ & $36.0 \%$ & Negotiated and obturated & Specialist \\
Buhrley et al. & $67.0 \%$ & $33.0 \%$ & Negotiated to working length & Graduate student \\
Hartwell et al.* & $70.2 \%$ & $\mathrm{n} / \mathrm{a}$ & Instrumentation and obturated & Junior resident \\
Corcoran et al. & $37.1 \%$ & $45.9 \%$ & Located and filled & Located and filled \\
Corcoran et al. & $62.1 \%$ & $62.5 \%$ & & Senior resident
\end{tabular}

*Studies showing percentage of teeth presenting four canals

Source: Studies are as follows: Hartwell G, Bellizzi R. Clinical investigation of in vivo endodontically treated mandibular and maxillary molars. J Endod 1982;8(12):555-7; Neaverth EJ, Kotler LM, Kaltenbach RF. Clinical investigation (in vivo) of endodontically treated maxillary first molars. J Endod 1987;13(10):506-12; Weller RN, Hartwell GR. The impact of improved access and searching techniques on detection of the mesiolingual canal in maxillary molars. J Endod 1989;15(2):82-3; Fogel HM, Peikoff MD, Christie WH. Canal configuration in the mesiobuccal root of the maxillary first molar: a clinical study. J Endod 1994;20(3):135-7; Zaatar El, al-Kandari AM, Alhomaidah S, al-Yasin IM. Frequency of endodontic treatment in Kuwait: radiographic evaluation of 846 endodontically treated teeth. J Endod 1997;23(7):453-6; Stropko JJ. Canal morphology of maxillary molars: clinical observations of canal configurations. J Endod 1999;25(6):446-50; Sempira HN, Hartwell GR. Frequency of second mesiobuccal canals in maxillary molars as determined by use of an operating microscope: a clinical study. J Endod 2000;26(11):673-4; Wolcott J, Ishley D, Kennedy W, et al. Clinical investigation of second mesiobuccal canals in endodontically treated and retreated maxillary molars. J Endod 2002;28(6):477-9; Buhrley LJ, Barrows MJ, BeGole EA, Wenckus CS. Effect of magnification on locating the MB2 canal in maxillary molars. J Endod 2002;28(4):324-7; Hartwell G, Appelstein CM, Lyons WW, Guzek ME. The incidence of four canals in maxillary first molars: a clinical determination. J Am Dent Assoc 2007;138(10):1344-6; and Corcoran J, Apicella MJ, Mines P. The effect of operator experience in locating additional canals in maxillary molars. J Endod 2007;33(1):15-7.

absence of an experienced attending endodontic faculty member in every case might have had a bigger negative influence compared to the positive impact of the D.O.M. In addition, due to the learning curve in using the D.O.M., endodontic residents can be considered inexperienced operators. ${ }^{25}$ Hartwell et al. in a similar clinical study among graduate students with endodontic faculty supervision found $70.2 \%$ of maxillary molars presenting four or more canals. ${ }^{18}$ Our findings were in agreement with Hartwell et al., suggesting that the assistance of an experienced professional seemed to be the most important element in helping dental students locate and treat MB2 canals.

To our knowledge, this study is the first to report MB2 canal location and treatment rates in a predoctoral endodontic clinical setting. Some dental schools do not allow dental students to perform root canal therapy on maxillary molars, partially due to the difficulty in locating and treating the MB2 canal. The results of our study showed that the rate of MB2 canals treated in our predoctoral clinic was similar to previous studies done in graduate endodontic clinics and private endodontic practices. Our results were achieved thanks to the use of magnification along with the presence of an experienced endodontic specialist. These results suggest that, under proper supervision by trained endodontists, it is safe for dental students to treat upper molars in a universitybased clinic. Further prospective clinical studies are necessary to help clarify the role of faculty in the location of MB2 canals and the obstacles that dental students face while locating and treating MB2 canals.

\section{Conclusion}

Our study found that, under proper supervision by experienced endodontists, third- and fourth-year dental students were capable of treating MB2 canals in maxillary molars. The frequency of MB2 canals located and treated by the students with the assistance of experienced professionals was higher in first maxillary molars than in second maxillary molars. No difference was found between the third- and fourth-year students. The incidence of MB2 canals located and treated in the clinic was similar to other reported clinical studies. 


\section{Disclosure}

The authors did not report any conflicts of interest related to this study.

\section{REFERENCES}

1. Schilder H. Cleaning and shaping the root canal. Dent Clin North Am 1974;18(2):269-96.

2. Song M, Kim HC, Lee W, Kim E. Analysis of the cause of failure in nonsurgical endodontic treatment by microscopic inspection during endodontic microsurgery. J Endod 2011;37(11):1516-9.

3. Wolcott J, Ishley D, Kennedy W, et al. A 5 yr clinical investigation of second mesiobuccal canals in endodontically treated and retreated maxillary molars. J Endod 2005; 31(4):262-4.

4. Park E, Chehroudi B, Coil JM. Identification of possible factors impacting dental students' ability to locate MB2 canals in maxillary molars. J Dent Educ 2014;78(5): 789-95.

5. Seijo MO, Ferreira EF, Sobrinho APR, et al. Learning experience in endodontics: Brazilian students' perceptions. J Dent Educ 2013;77(5):648-55.

6. Stropko JJ. Canal morphology of maxillary molars: clinical observations of canal configurations. J Endod 1999;25(6):446-50.

7. Corcoran J, Apicella MJ, Mines P. The effect of operator experience in locating additional canals in maxillary molars. J Endod 2007;33(1):15-7.

8. Buhrley LJ, Barrows MJ, BeGole EA, Wenckus CS. Effect of magnification on locating the MB2 canal in maxillary molars. J Endod 2002;28(4):324-7.

9. Hasan M, Khan FR. Determination of frequency of the second mesiobuccal canal in the permanent maxillary first molar teeth with magnification loupes (x 3.5). Int J Biol Sci 2014;10(3):201-7.

10. Rampado ME, Tjaderhane L, Friedman S, Hamstra SJ. The benefit of the operating microscope for access cavity preparation by undergraduate students. J Endod 2004;30(12):863-7.

11. Yoshioka T, Kikuchi I, Fukumoto Y, et al. Detection of the second mesiobuccal canal in mesiobuccal roots of maxillary molar teeth ex vivo. Int Endod J 2005;38(2):124-8.
12. Alacam T, Tinaz AC, Genc O, Kayaoglu G. Second mesiobuccal canal detection in maxillary first molars using microscopy and ultrasonics. Aust Endod J 2008;34(3):106-9.

13. Brullmann DD, Weichert CI, Daublander M. Intraoral cameras as a computer-aided diagnosis tool for root canal orifices. J Dent Educ 2011;75(11):1452-7.

14. Smadi L, Khraisat A. Detection of a second mesiobuccal canal in the mesiobuccal roots of maxillary first molar teeth. Oral Surg Oral Med Oral Pathol Oral Radiol Endod 2007;103(3):77-81.

15. Kulild JC, Peters DD. Incidence and configuration of canal systems in the mesiobuccal root of maxillary first and second molars. J Endod 1990;16(7):311-7.

16. Fogel HM, Peikoff MD, Christie WH. Canal configuration in the mesiobuccal root of the maxillary first molar: a clinical study. J Endod 1994;20(3):135-7.

17. Sempira HN, Hartwell GR. Frequency of second mesiobuccal canals in maxillary molars as determined by use of an operating microscope: a clinical study. J Endod 2000;26(11):673-4.

18. Hartwell G, Appelstein CM, Lyons WW, Guzek ME. The incidence of four canals in maxillary first molars: a clinical determination. J Am Dent Assoc 2007;138(10):1344-6.

19. Zaatar EI, al-Kandari AM, Alhomaidah S, al-Yasin IM. Frequency of endodontic treatment in Kuwait: radiographic evaluation of 846 endodontically treated teeth. J Endod 1997;23(7):453-6.

20. Vertucci FJ. Root canal anatomy of the human permanent teeth. Oral Surg Oral Med Oral Pathol 1984;58(5):589-99.

21. Cleghorn BM, Christie WH, Dong CC. Root and root canal morphology of the human permanent maxillary first molar: a literature review. J Endod 2006;32(9):813-21.

22. Wolcott J, Ishley D, Kennedy W, et al. Clinical investigation of second mesiobuccal canals in endodontically treated and retreated maxillary molars. J Endod 2002;28(6):477-9.

23. Das S, Warhadpande MM, Redij SA, et al. Frequency of second mesiobuccal canal in permanent maxillary first molars using the operating microscope and selective dentin removal: a clinical study. Contemp Clin Dent 2015;6(1):74-8.

24. De Carvalho MC, Zuolo ML. Orifice locating with a microscope. J Endod 2000;26(9):532-4.

25. Bowers DJ, Glickman GN, Solomon ES, He J. Magnification's effect on endodontic fine motor skills. J Endod 2010;36(7):1135-8 